\title{
DESCUBRIMIENTOS ARQUEOLÓGICOS EN EL ANFITEATRO DE ITÁLICA EN 1914
}

\section{ARCHAEOLOGICAL DISCOVERIES IN THE ITALICA AMPHITHEATRE FROM 1914}

\author{
por
}

JOSÉ BELTRÁN FORTES

RESUMEN Se revisa una serie de piezas arqueológicas aparecidas en las excavaciones del anfiteatro de Itálica en 1914, a partir de anotaciones inéditas de José Gestoso y Pérez y José Ramón Mélida.

\begin{abstract}
We review some archaeological pieces of the excavation of Italica's Amphitheater in 1914, from unpublished papers of José Gestoso y Pérez and José Ramón Mélida.
\end{abstract}

Palabras claves Itálica. Historiografía. Anfiteatro. Culto egipcio.

Key words Italica. Historiography. Amphiteather. Egyptian Cult.

"En 1977 nos hicimos cargo de la dirección de las excavaciones de Itálica, habiendo presentado un proyecto de trabajo, a realizar en tres años, consistente en el estudio estratigráfico del viejo emplazamiento, la delimitación del perímetro amurallado de la ciudad, el estudio de la red de cloacas y de sus estructuras y la localización y excavación de la cisterna de la 'nova urbs'." (Pellicer 1982: 207).

Con estas palabras resumía el profesor Pellicer sus actividades arqueológicas en la ciudad romana de Itálica durante los años 1977-1979. La labor de M. Pellicer durante aquellos años, a la vez que ofrece un claro exponente de su amplitud de miras en la investigación arqueológica, continuaba un largo número de trabajos de excavación en el yacimiento, que se remontaría cuando menos al siglo XVIII, aunque -claro está-con otros planteamientos y objetivos totalmente diversos ${ }^{1}$. A pesar de que no se incluía en ese "proyecto

1. Realmente las primeras "excavaciones" seguras se sitúan en esa centuria ilustrada (por ejemplo, las de Manuel Martí a comienzos de siglo o, especialmente, las del conde del Águila y Francisco de Bruna en la segunda mitad), aunque en los dos siglos anteriores existiera un gran interés por las ruinas italicenses, que habían sido consideradas como "Sevilla la vieja". Sobre la historia 
de trabajo" ninguna actuación sobre el anfiteatro italicense, la colosalidad e importancia de este edificio había sido el motivo de que buena parte de las actuaciones realizadas con anterioridad en el yacimiento se hubieran concentrado precisamente en el anfiteatro (Rodríguez Hidalgo 1991: 91-94). Ha sido y sigue siendo, sin duda, el edificio emblemático del yacimiento.

Es por ello que me sumo al Homenaje rendido al profesor Pellicer en la Universidad de Sevilla con unas breves notas sobre algunos descubrimientos producidos en los trabajos arqueológicos realizados en el anfiteatro de Itálica en 1914. En efecto, entre los papeles pertenecientes a José Gestoso y Pérez ${ }^{2}$ que se guardan en la Biblioteca Capitular y Colombina de Sevilla se conserva un breve informe elaborado en 1915 por este erudito sevillano referido a algunos descubrimientos arqueológicos que tuvieron lugar en el anfiteatro de Itálica durante los trabajos de limpieza que se realizaron en el edificio en los últimos meses del año anterior de $1914^{3}$. El interés radica tanto en la constatación del contexto de aparición de tales piezas, como en el hecho de que incluye la opinión del importante y pionero arqueólogo español José Ramón Mélida sobre una de ellas, que le había comunicado epistolarmente a Gestoso y Pérez.

Como es sabido, fueron especialmente sobresalientes las excavaciones que el arquitecto Demetrio de los Ríos llevó a cabo en el anfiteatro a partir del año 1860, vinculadas a la labor de la Comisión Provincial de Monumentos Históricos y Artísticos de Sevilla y que dieron lugar sólo dos años después a la publicación de una importante monografía para la época ${ }^{4}$. Tras el traslado de D. de los Ríos a León, en 1880, se produjo cierto descontrol en los trabajos del anfiteatro, desarrollándose variadas labores de excavación, que casi siempre fueron simples desescombros poco conocidos ya que generaron escasa bibliografía. Algunos fueron llevados a cabo por parte de miembros de la Comisión de Monumentos de Sevilla, como el propio José Gestoso, junto a Francisco Caballero-Infante, en el año 1886, y especialmente por uno de los guardas de las ruinas del anfiteatro, Manuel Fuentes, realizados de forma paulatina durante el último cuarto del siglo XIX y hasta 1912. De forma paralela los años finales del siglo XIX conocieron un auge de las excavaciones en Itálica llevados a cabo por eruditos locales, como Francisco Aurelio Álvarez, que en 1898 asimismo excavó en el anfiteatro, o por extranjeros, arqueólogos o simples coleccionistas; entre los primeros podemos citar a Arthur Engel, que excavó en 1890 -asociado al erudito sevillano Antonio María Ariza, también de la Comisión de Monumentos sevillana-en diversos lugares del yacimiento, pero no en el anfiteatro; entre los segundos, un buen ejemplo lo supone el americano Archer Milton Huntington, que costeó excavaciones también en 1898 para obtener piezas para sus colecciones ${ }^{5}$.

Los comienzos del nuevo siglo XX no cambiaron la situación y el coleccionismo italicense tiene entonces un paradigmático exponente en la colección sevillana de Regla Manjón, condesa de Lebrija (Lleó 1994), a la par que - de nuevo desde la Comisión de Monumentos de Sevilla- dirige Manuel Fernández López unas excavaciones en la llamada necrópolis de "La Vegueta" (Fernández López 1903).

La situación cambiará ya en 1911, con la primera Ley de Excavaciones, que controlaba en cierto modo esas actuaciones y que fue desarrollada mediante un Reglamento en 1912, con la creación de la Junta Superior de Excavaciones y Antigüedades (Beltrán 1995: 53s.). Aquel año de 1912 fueron declaradas Monumento Nacional las "Ruinas de Itálica", entre las que destacaba el anfiteatro, y entonces comenzaron las excavaciones de Rodrigo Amador de los Ríos, quien tuvo la dirección "de las excavaciones dispuestas por el Gobierno"

\footnotetext{
de las actuaciones en Itálica, hasta el siglo XX, puede verse ahora León 1993: 29-62; Luzón 1999; Caballos, Marín, Rodríguez Hidalgo 1999: 37-50.

2. Vid., infra, nota 10. Sobre el personaje cfr. Rodríguez Jurado 1918; Pleguezuelo 1995: VIII-XXIII.

3. Gestoso 1914: 38-39 y $42-43$.

4. Ríos 1862. Existe en la Biblioteca Nacional de Madrid el manuscrito inédito de una historia de Itálica que preparaba este autor, cuyas láminas se encuentran en el Museo Arqueológico Provincial de Sevilla y han sido dadas a conocer por Fernández Gómez 1998.

5. De forma en parte coetánea a estos trabajos el interés erudito (con evidentes ribetes periodísticos) por las ruinas queda expuesto en una obra como la dedicada a la historia de la ciudad por Gali (1892).
} 
(Ríos 1916 a: 404), pero que debieron compaginarse con actuaciones complementarias llevadas a cabo por la Comisión de Monumentos de Sevilla, con la que entraría en conflicto algún tiempo después ${ }^{6}$. El propio Rodrigo Amador de los Ríos recuerda la existencia de una “...gavia que, para desviar del Anfiteatro las aguas que en él por el Ocaso vierten y la inundan, logré en 1914 abriese... la Comisión Provincial de Monumentos de Sevilla..." (Ríos 1916 b: 10).

Ese mismo año de 1914 la Comisión sevillana, bajo la dirección de su miembro más conspicuo en el campo arqueológico, el vicepresidente José Gestoso y Pérez ${ }^{7}$, llevó a cabo también las tareas de desescombro en la zona central de la arena y del pasillo subterráneo y abovedado que se extendía hacia la entrada oriental ${ }^{8}$. No debe olvidarse que -como se dijo- Gestoso había ya realizado, en 1886, junto a Caballero-Infante, exploraciones en el centro de la arena, que fueron continuadas por el guarda de las ruinas Manuel Fuentes y culminadas en aquellos momentos del nuevo siglo ${ }^{9}$.

Como ha indicado A. Pleguezuelo (1995: XV-XVI) sobre Gestoso:

"Su calidad de Académico de la Real de Bellas Artes y de Buenas Letras de Sevilla, de correspondiente de la de San Fernando de Madridy, sobre todo, su cargo como Vicepresidente en la Comisión Provincial de Monumentos, le convirtieron literalmente en el árbitro indiscutible de cuantas obras se emprendieron en la ciudad en el terreno patrimonial entre 1878 y 1917.

Entre ellas sobresalen la ampliación del edificio del Ayuntamiento, las obras acometidas en los Reales Alcázares, las excavaciones de Itálica, la construcción en aquél conjunto de una Casa-Museo romana proyectada por él, las remodelaciones del Museo Provincial de Bellas Artes o la misma creación del Museo Arqueológico Municipal, realizada a iniciativa suya y en cuyo primer catálogo, encargado en 1878 a Don Demetrio de los Ríos, colaboró junto a Don Leoncio Baglietto y Don Francisco Mateos Gago."

Como resultados de aquellos trabajos citados en el anfiteatro de Itálica se descubrieron algunas piezas arqueológicas de interés, que quedan referidas en el breve informe manuscrito ya referido que firma José Gestoso en 1915 y que se conserva entre sus papeles de la Biblioteca Capitular y Colombina de Sevilla, que pasamos a reproducir íntegramente ${ }^{10}$, así como las fotografías que se incluyen en él, el retrato femenino (lám. I) y el fragmento de estatuilla egipcia (láms. II-III):

6. Sobre todo en 1915 con motivo de la construcción de un edificio de museo que la Comisión (especialmente Gestoso) veló porque se construyera en el ámbito del anfiteatro y que fue criticada por R.A. de los Ríos. Éste, en el marco de aquella disputa, que refleja la prensa sevillana del momento, achacaba las envidias de los eruditos sevillanos a que la dirección de los trabajos en Itálica hubiera sido encómendada a alguien venido de Madrid. Asimismo se refiere a ello en su memoria: Ríos 1916 b: 20.

7. Las Comisiones siempre estuvieron presididas por los correspondientes gobernadores provinciales-seguramente como una válvula de control político-, por lo que de hecho la figura del Vicepresidente era la más significativa desde el punto de vista académico o científico.

8. Rodrigo Amador de los Ríos (1916b: 6-9) refiere su excavación previa del pasillo superior que conducía a la entrada occidental, en el que identificó las claraboyas que daban luz al pasillo subterráneo. También cita que "las últimas exploraciones efectuadas por la Comisión Provincial de Monumentos han dejado en la fossa al descubierto el pavimento de la parte limpia, el cual es de vulgares losetas de ladrillo..." (Ríos 1916 b: 17).

9. A ellas se refiere Gestoso 1892:612-615. Como ejemplo del enfrentamiento entre Rodrigo Amador de los Ríos y la Comisión Provincial sevillana -y especialmente con Gestoso-el primero criticó la interpretación dada por éste a los restos exhumados entonces (Ríos 1916 a: 403).

10. Se encuentra en el tomo XXXVI de los Papeles Varios del "Fondo Gestoso", fechado en la portada en 1914, aunque el encabezamiento del informe se refiere, en efecto, a los años 1914-15. Además, el informe se encuentra encuadernado en dos partes separadas: en los fols. 42s. las primeras páginas, con las fotos del retrato femenino (fol. 44) y de la estatuilla egipcia (fols. 44v-45r) -que reproducimos ahora-, y en los fols. 38-39 el final del informe. 
"Durante los meses de octubre a diciembre de 1914, dispuso la Comisión de Monumentos extraer todo el barro que macizaba la construcción subterránea del centro del Anfiteatro y de la gran bóveda situada al Poniente ${ }^{11}$, a la mediación de la cual fue encontrada primeramente la cabeza de mujer esculpida en mármol blanco, cuya fotografía acompaña, y pocos días después la mitad inferior de estatuita egipcia, acerca de la cual escribió D. José Ramón Mélida en $1^{\circ}$ de enero de 1915. 'Ya me sorprendió la noticia del hallazgo en Itálica de una escultura egipcia, pero mas me ha llenado de estupefacción la fotografía de la misma. De no decirme $V$. que sus obreros lo encontraron (en los que supongo tendrá $V$. confianza, y por tanto no será admisible digan haber encontrado lo que de intento colocaron) creería que se trataba de uno de esos hallazgos preparados para desorientar a los arqueólogos, creo que ya se ha dado más de una vez en España.

Contadísimas y pequeñas son las cosas de origen egipcio encontradas en nuestra Península, no siendo justificable su presencia más que por el comercio fenicio.

Pide V. mi opinión y aunque poco vale voy a dársela con la salvedad natural de que juzgo por fotografía y no por el original, que según V. me dice es de granito pulimentado como los egipcios supieron hacerlo solamente. Veo se trata de un fragmento de estatua de cintura a poco mas bajo que la rodilla, no de mujer sino de hombre, con su obligada ceñida y corta vestidura, el schenti o paño pendiente de la cintura y ajustado a las caderas, listado, pero de varonil bien caracterizado. El personaje está sentado en un trono, con el brazo izquierdo sobre el muslo. El derecho pudo estar lo mismo o mas probablemente doblado sobre el pecho y en la mano derecha acaso tuviera un atributo. Pudo y debió ser una imagen de Ra o de Ammon o de Ammon-Ra o de Horus, del Sol, en su ma, al que no hay que olvidar adoraron también los fenicios. Pero el trabajo es puramente egipcio y no del lamido estilo ptolemaico, que nos llevaría a admitir sin violencia una importación romana, sino del estilo hierático del nuevo Imperio, de las dinastías XVIII si se quiere a la XXII (siglos XV al $X$ antes de J.C.) es decir, de una época en que solamente los fenicios pueden haber importado de Egipto tal estatua. Respecto que ésta es hierática, de un trabajo firme y vigoroso que recuerda el de las esculturas mejores de esa época (el Amenofis IV del Louvre, el Ramsés II de Turín, los colosos, etc.) y de un estilo que me parece bastante puro. Es en suma una buena cosa y por el hallazgo felicito a $V$.'

Además de estos dos objetos, tan interesantísimo el segundo por ser el único egipcio encontrado en Itálica, hallaron también los trabajadores que limpiaban la bóveda un pequeño altar o ara de mármol blanco toscamente esculpido y en esta forma y adornados sus cuatro frentes por distintos motivos: en uno el prefericulo, en otro la patera, y en los dos restantes una corona de laurel y unos frutos. Medirá próximamente de alto unos $14 \mathrm{~cm}$ por 8 . Debe también mencionarse una mano de barro encarnado sujetando un paño, mitad del natural, mutilada.

En los últimos días de enero de 1915 se llegó al pavimento de la construcción subterránea del anfiteatro, que es de robusto ladrillo del tipo corriente a los empleados en las construcciones italicenses; y en dicha solería aparecieron varios fragmentos de vigas negras y carcomidas al punto de no conservar más que los nudos y el corazón, y también infinidad de trozos de mármoles de colores, como de grandes losas y varias de éstas de gran tamaño de las llamadas jabalunas, con muchos pedazos de fustes de tamaño mediano de mármol sanguíneo" (Gestoso 1914: 38-39 y 42-43).

Las tres primeras piezas citadas fueron enviadas en dos entregas de la Comisión de Monumentos al Museo Arqueológico de Sevilla el mismo año de 1914-y en sus salas se exponen actualmente-, aunque no hemos podido localizar la citada "mano de barro... sujetando un paño".

11. Se trata sin duda de un error, ya que el descubrimiento tuvo lugar en la entrada oriental, como se recoge en la carta que reproducimos a continuación. 
El primer ingreso se cita en una carta dirigida por Gestoso, como vicepresidente de la Comisión, al Director del Museo Manuel Campos Munilla, fechada el 13 de noviembre de 1914:

"En Junta celebrada el 12 de los corrientes por esta Corporación, se acordó hacer entrega a V.S.I. en calidad de depósito, de la cabeza de mármol blanco de mujer, hallada en la bóveda subterránea situada en el extremo de oriente del Anfiteatro de Italica, con motivo de la limpieza que en dicho sitio se efectúa actualmente por esta Comisión, y cuyas fotografias van adjuntas al presente oficio..." ${ }^{12}$.

Algo después, en carta del mismo Gestoso a Campos Munilla fechada el 28 de diciembre de 1914 se refiere el envío de las otras dos piezas:

"En cumplimiento de acuerdo de esta Comisión envío a V.S.I. un fragmento, parte inferior mutilada de estatuita de mujer egipcia, en actitud sedente esculpida en granito gris, recientemente encontrada en el Anfiteatro de Itálica, de cuya misma procedencia es también una pequeña ara de mármol blanco que asimismo le remito en calidad de depósito hasta tanto que la Junta Superior de Excavaciones determine donde deberán ser conservados dichos objetos..." ${ }^{13}$.

A pesar de tales referencias no ha sido hasta fechas recientes que se ha destacado para las dos esculturas la circunstancia de su descubrimiento en el anfiteatro. El retrato femenino corresponde a la conocida pseudoOctavia, ya que como representación de la hermana de Augusto fue considerada durante mucho tiempo, hasta que Pilar León la interpretó de forma correcta simplemente como una particular que sigue el modelo de aquélla y la vinculó a su lugar concreto de descubrimiento (León 1995: 84 s., n² 24; León 2001: 150-153, $\left.n^{\circ} 39\right)$. La fecha de elaboración de la escultura en época augústea obliga de forma inevitable a una justificación de su presencia en el anfiteatro adrianeo, que esta misma autora plantea de forma adecuada:

"El hallazgo de la cabeza en uno de los edificios públicos más representativos de la Nova Urbs adrianea, el Anfiteatro, representa una aparente distorsión a causa de la distancia cronológica. Buscarle explicación con el azaroso devenir de las piezas en un yacimiento tan expoliado como Itálica es un recurso fácil, aunque dada la proximidad de alguna de las necrópolis italicenses, puede ser verosímil" (León 1995: 84).

La procedencia en el anfiteatro de las otras dos piezas asimismo establece interesantes consideraciones sobre sus respectivos contextos originales. En efecto, como indicaba P. León sería un recurso fácil interpretarlas sólo como fruto de una genérica descontextualización de las piezas, sobre todo por diversos factores. En primer lugar, el carácter de ambas, un arula anepigráfica y una estatuilla egipcia, que no son apropiadas en principio para originales contextos sepulcrales, como ocurre con el retrato. En segundo lugar, podría

12. Archivo del Museo Arqueológico de Sevilla, año 1914, carta de 13 de noviembre, que, en efecto se acompaña de dos fotografías de la escultura reseñada. En ese mismo legajo hay copia de la carta de respuesta el mismo 13 de noviembre a la Comisión de la recepción de la escultura. En otra carta de 8 de diciembre de 1914, que se conserva en los fondos de la Comisión de Monumentos de Sevilla (hoy en la biblioteca de la Real Academia de Bellas Artes de Sevilla), también se refiere Gestoso a estos descubrimientos, indicando que aparecieron "..entre el barro que se extrae de una bóveda del Anfiteatro..", aunque erróneamente cita el retrato marmóreo como "cabeza de una ninfa".

13. Archivo del Museo Arqueológico de Sevilla, año 1914, carta de 28 de diciembre. Asimismo se conserva en el legajo la carta de respuesta del Director del Museo dirigida a la Comisión con la fecha del mismo día, donde se describen ambos objetos en los siguientes términos: "El primero es de mármol blanco, de forma rectangular, decorado con relieves y su altura 0,17 . El segundo es un fragmento mutilado, parte inferior de una estatuita de persona sentada, de estilo egipcio, esculpida en piedra". La frase tachada aparece en la copia, quizás porque Campos Munilla dudó finalmente de la clasificación. 
pensarse que corresponden a piezas llevadas al Anfiteatro, de forma intencionada o no, desde otros sectores de la ciudad, en concreto de las domus situadas al norte de la "Nova Urbs". No obstante, el propio devenir histórico del enclave en los momentos tardoantiguos, con el abandono desde el siglo III d.C. de buena parte del sector septentrional del ensanche urbano adrianeo, mientras que el anfiteatro seguiría en funcionamiento durante el siglo IV d.C. (Rodríguez Hidalgo y otros 1999: 73-97), parece hacer menos plausible la explicación de un simple arrastre de depósitos desde alguna de las domus una vez que el anfiteatro quedó fuera de uso ${ }^{14}$. En tercer lugar, la existencia de un espacio de culto ubicado en el anfiteatro, que se ha considerado tradicionalmente como un nemeseion, por diversos exvotos dirigidos a Nemesis Augusta, pero en el que coexistieron más cultos, en el mismo recinto o en recintos diversos. De forma constatada existía un santuario dedicado a la diosa norteafricana Dea Caelestis y, quizás, también se adoraban otras divinidades. En ese marco cultual es posible que tuvieran cabida en el anfiteatro la presencia de ambas piezas, un arula y la representación de una divinidad egipcia, aunque este planteamiento es de difícil corroboración y siempre nos movemos en el plano hipotético. De cualquier forma a todas esas cuestiones nos hemos referido en fecha reciente y a ese trabajo remitimos para su análisis (Beltrán y Rodríguez Hidalgo e.p.).

Sí haré para finalizar algunas consideraciones breves sobre el interés de J.R. Mélida por la estatuilla egipcia y por los datos enriquecedores que ésta aporta en el contexto italicense. La consulta de Gestoso a Mélida, anticuario del Museo Arqueológico Nacional de Madrid desde 1876 y, a partir de 1901, director del Museo de Reproducciones Artísticas, estaba justificada porque se trataba de uno de los arqueólogos españoles que más se habían dedicado por la egiptología durante el último cuarto del siglo XIX. Siguiendo la estela de su maestro Juan de Dios de la Rada Delgado en su interés por el estudio del Antiguo Egipto, intentó Mélida la dotación de una cátedra de egiptología y, además, fue el autor de una Historia del Arte Egipcio, que se editó en Madrid en 1899; en el prólogo de dicha obra el autor indica que estaba dedicado a su estudio desde hacía más de veinte años. No obstante, ya por los años 1914-15 sus intereses se dirigían en otros sentidos. Como afirma Almela Boix (1991: 132), “... a partir de la negativa oficial para la creación de dicha cátedra, por falta de presupuestos, en 1900, Mélida no vuelve a publicar ningún trabajo sobre arqueología egipcia, ni, que sepamos, a continuar sus estudios en esta línea".

La esculturilla egipcia de Itálica ha sido estudiada en fecha reciente por I. Gamer-Wallert ${ }^{15}$, en unas conclusiones que revisan las consideraciones de Mélida expuestas a vuela pluma y sólo a partir de fotografías. Sí acertaba éste en considerarlo representación de una divinidad masculina entronizada, aunque para Mélida serían Amón-Ra o Horus, mientras que la citada autora se inclina por Ptah, el propio Amón o Anubis. Además, amén de que está elaborada la pieza no en granito (como indicaba Gestoso) sino en serpentina, la cronología no correspondería al Imperio Nuevo sino a la Época Tardía, concluyendo Gamer-Wallert (1998:9) “...que la estatua pudo realizarse probablemente hacia el segundo cuarto del I milenio a.C., y no en época posterior. Su llegada a la Península Ibérica, quizás procedente del Delta del Nilo, podría haber tenidolugar en época romana".

Siguiendo esa última consideración, la estatuilla es de elaboración egipcia (no egiptizante de época romana) y se integra dentro del proceso bien conocido en la sociedad romana de reutilización de piezas originales egipcias con finalidad ornamental o cultual. En este caso, dado que se trata de una representación de una divinidad es más plausible que tuviera un uso cultual. Gracias a los trabajos de excavación de Ramón Corzo en el teatro de Itálica hoy sabemos de la existencia de un pequeño santuario dedicado al culto de

14. De hecho el arula podría interpretarse perfectamente como apropiada para el culto doméstico, lo que refrendaria su carácter anepigráfico, pero asimismo puede interpretarse como exvoto en un santuario público situado en el anfiteatro. $O$ incluso en una reutilización en época tardorromana de una pieza elaborada anteriormente, un fenómeno bien constatado en santuarios romanos de los siglos III-IV d.C. Ese carácter de reutilización es obvio en el caso de la estatuilla egipcia.

15. Gamer-Wallert 1998: 6-9, quien sí indica que procede del anfiteatro de Itálica, pero asimismo "...que apareció en las excavaciones que en el año 1914 se llevaron a cabo en la zona del anfiteatro, bajo la dirección de D. Rodrigo Amador de los Ríos... pero sin ningún dato complementario sobre el lugar concreto de aparición o circunstancias." (Ibid.: 6). 
Isis que, en la segunda mitad del siglo II d.C., se construyó en la zona norte del pórtico posterior del edificio teatral (Corzo 1991: 125-148). Evidentemente no tiene ello que suponer que la estatuilla hubiera estado originalmente ubicada en este santuario, sino que documenta la significativa introducción del culto egipcio en Itálica, que previamente no estaba documentado ${ }^{16}$. Sobre la ubicación original de la pieza sirven las consideraciones que habíamos expuesto más arriba e incluso la hipótesis de que hubiera estado situada en un santuario del propio anfiteatro, donde -como ya hemos resaltado (Beltrán y Rodríguez Hidalgo e.p.)el nemeseion no debió ser el único espacio de culto.

\section{BIBLIOGRAFÍA}

ALMELA BOIX, A. (1991): "La aportación de José Ramón Mélida a la consolidación de la Arqueología como disciplina científica en España", en J. Arce, R. Olmos, eds., Historiografía de la Arqueología y de la Historia Antigua en España (Siglos XVIII-XX). Congreso Internacional: 131-134, Madrid.

ALVAR EZQUERRA, J. (1994): “La sociedad y el culto: Isis en la Bética”, en C. González Román, ed., La sociedad de la Bética. Contribuciones para su estudio: 9-28, Granada.

BELTRÁN FORTES, J. (1995): “Arqueología y configuración del patrimonio andaluz. Una perspectiva historiográfica", en F. Gascó y J. Beltrán, eds., La antigüedad como argumento. II. Historiografía de arqueología e historia antigua en Andalucia: 13-56, Sevilla.

BELTRÁN FORTES, J. y RODRÍGUEZ HIDALGO, J.M. (en prensa): Espacios de culto en el anfiteatro de Itálica, Sevilla.

CABALLOS RUFINO, A., MARÍN FATUARTE, J. y RODRÍGUEZ HIDALGO, J.M. (1999): Itálica Arqueológica, Sevilla.

CORZO SÁNCHEZ, R. (1991): "Isis en el teatro de Itálica", Boletín de Bellas Artes de Sevilla XIX: 125-148.

FERNÁNDEZ GÓMEZ, F. (1998): Las excavaciones de Itálica y Don Demetrio de los Ríos a través de sus escritos, Córdoba.

FERNÁNDEZ LÓPEZ, M. (1903): Excavaciones en Itálica, Sevilla.

GALI LASSALETTA, A. (1892): Historia de Itálica, Sevilla.

GAMERT-WALLERT, I. (1998): "Una deidad del antiguo Egipto en Itálica", Revista de Arqueología, $\mathrm{n}^{\circ}$ 206, junio: 6-9.

GESTOSO PÉREZ, J. (1892): Sevilla Monumental y Artística, Sevilla.

- (1914): "Descubrimientos en Itálica (1914-1915)", Papeles Varios, "fondo Gestoso" de la Biblioteca Capitular y Colombina de Sevilla, tomo XXXVI: 38-39 y 42-44.

LEÓN ALONSO, P. (1993): “Las ruinas de Itálica. Una estampa arqueológica de prestigio”, en J. Beltrán y F. Gascó, (eds.), La antigüedad como argumento. Historiografía de Arqueología e Historia Antigua en Andalucia: 29-62, Sevilla.

- (1995): Esculturas de Itálica, Sevilla.

- (2001): Retratos romanos de la Bética, Sevilla.

LLEÓ CAÑAL, V.(1995): La casa sevillana de los Condes de Lebrija y el coleccionismo romántico, Sevilla. LUZÓN NOGUÉ, J.M. (1999): Sevilla la Vieja. Un paseo histórico por las ruinas de Itálica, Sevilla.

PELLICER CATALÁN, M. (1982): "Excavaciones en Itálica (1978-1979). Muralla, cloacas y cisterna", en P. León (ed.), Itálica (Santiponce, Sevilla). Actas de las Primera Jornadas sobre Excavaciones Arqueológicas en Itálica, Excavaciones Arqueológicas en España n 121: 205-224, Madrid.

PLEGUEZUELO, A. (1995): "Presentación", en J. Gestoso y Pérez, Historia de los barros vidriados sevillanos. Desde sus orígenes hasta nuestros días [Sevilla, 1904]: VIII-XXIII, Sevilla (reed.).

16. Sobre el desarrollo del culto de Isis en la Bética, donde sobresale el Iseo de Baelo Claudia, cfr. Alvar 1994: 9-28. 
RÍOS, D. DE LOS (1862): Memoria Arqueológica Descriptiva del Anfiteatro de Itálica, Madrid.

RÍOS, R.A. (1916 a y b): "El anfiteatro de Itálica", RABM XXX: 381-410 y 1-24.

RODRÍGUEZ HIDALGO, J.M. (1991): "Sinopsis historiográfica del Anfiteatro de Itálica”, en Arce, J. y Olmos, R. (eds.), Historiografía de la Arqueología y de la Historia Antigua en España (Siglos XVIII-XX). Congreso Internacional: 91-94, Madrid.

RODRÍGUEZ HIDALGO, J.M. y otros (1999): "La Itálica de Adriano", AEspA 72: 73-97.

RODRÍGUEZ JURADO, A. (1918): Homenaje rendido a la memoria del Excelentísimo Señor D. José Gestoso y Pérez. Discurso necrológico. Sevilla. 


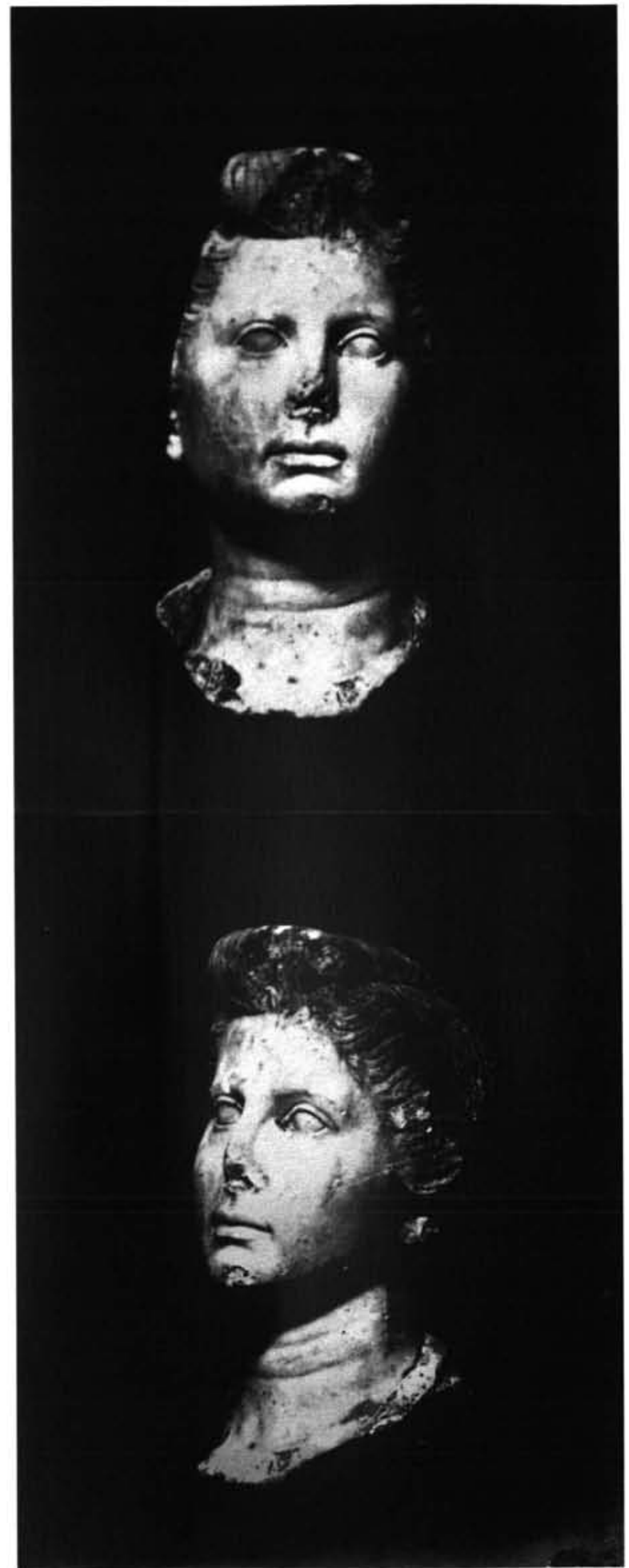

Lám. I. Retrato femenino ("pseudo-Octavia") aparecido en el Anfiteatro de Itálica, según fotografías de 1914 de J. Gestoso y Pérez. 


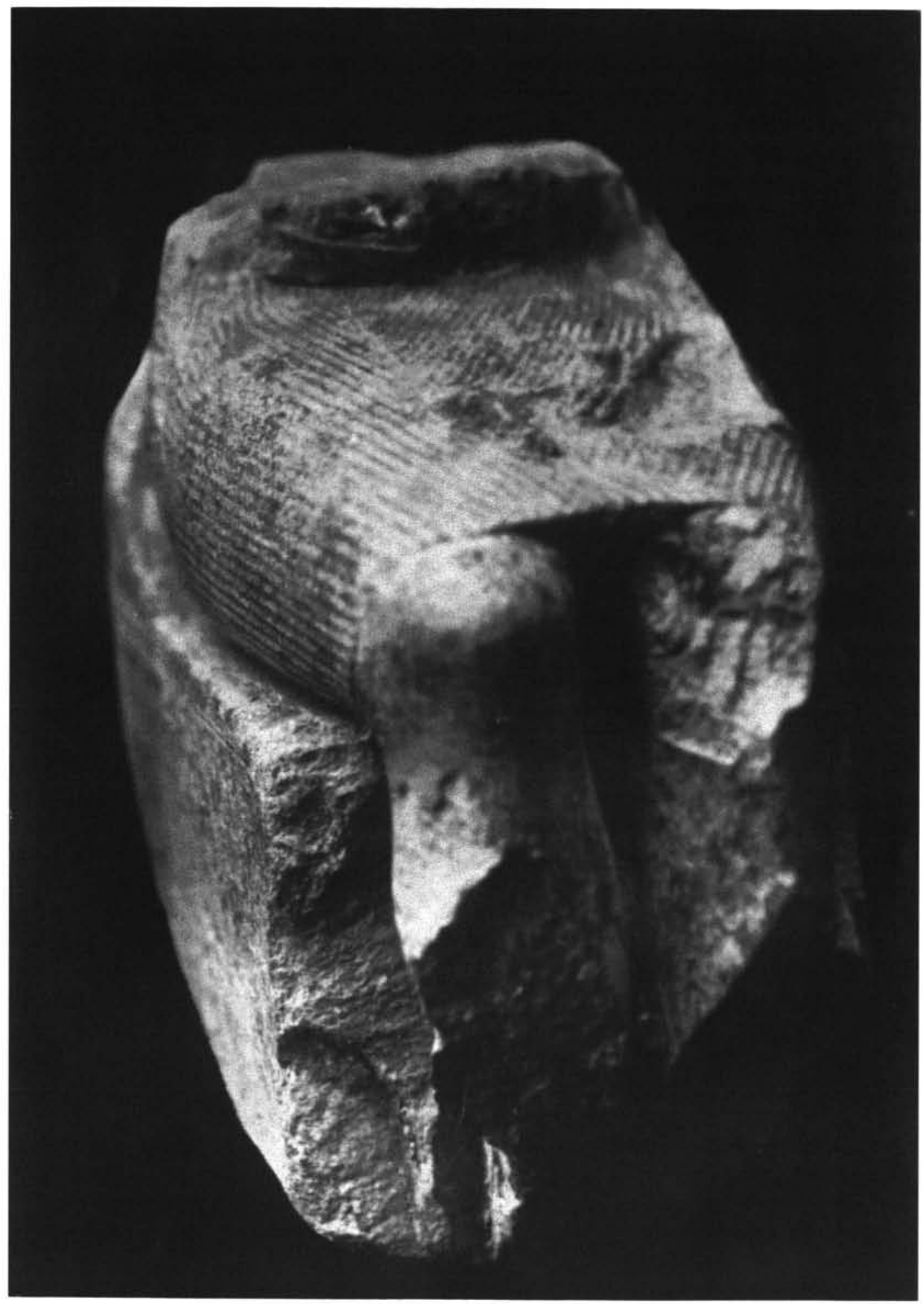

Lám. II. Fragmento de estatuilla egipcia aparecida en el Anfiteatro de Itálica, según fotografía de J. Gestoso y Pérez (1914). 

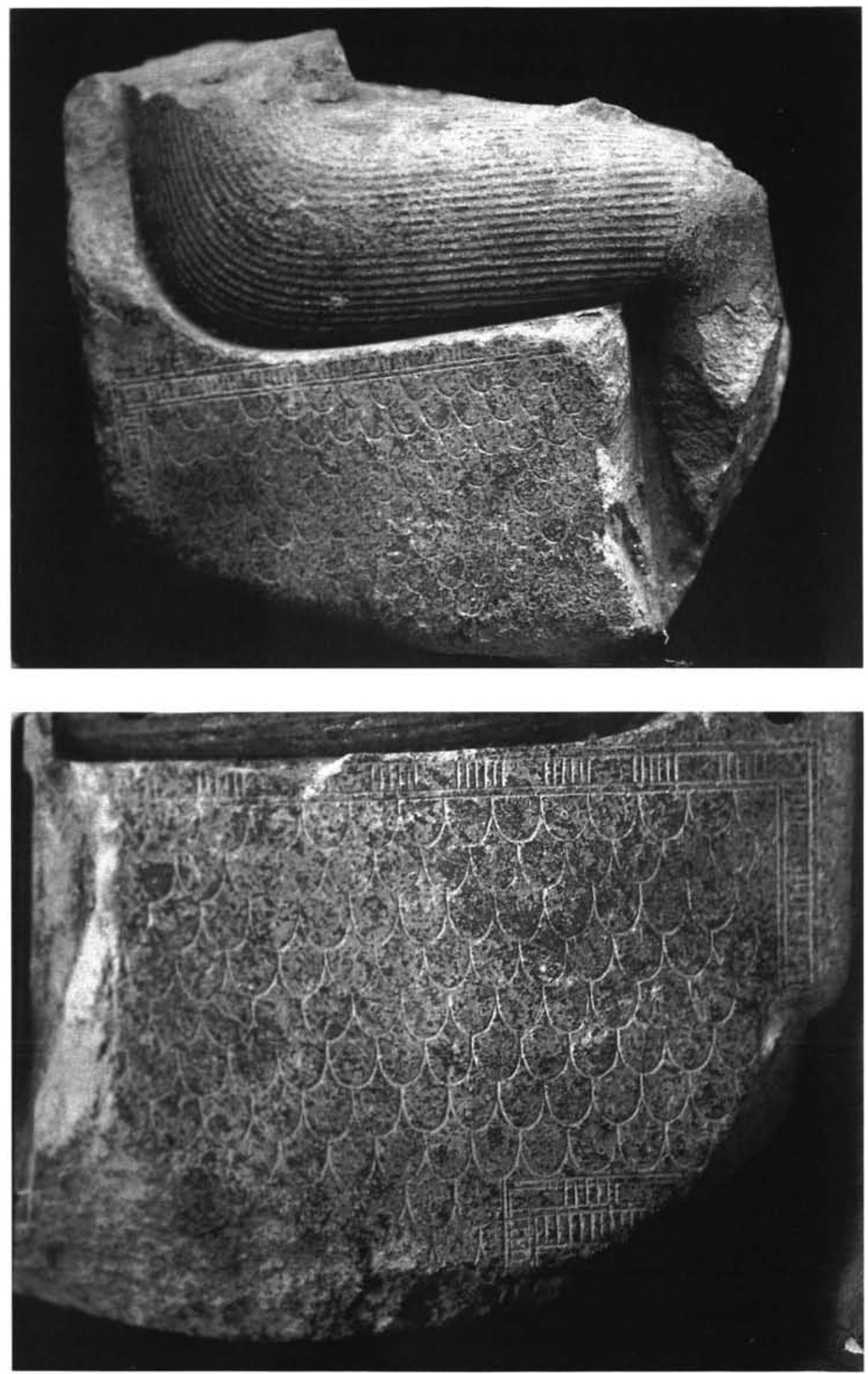

Lám. III. Ídem., fotografías de J. Gestoso y Pérez (1914) del lateral de la estatuilla y detalle de la decoración del trono. 